\title{
Vulnerability of cloud forest reserves in Mexico to climate change
}

\author{
Rocío Ponce-Reyes ${ }^{1 \star}$, Víctor-Hugo Reynoso-Rosales ${ }^{2}$, James E. M. Watson ${ }^{1,3}$, Jeremy VanDerWal ${ }^{4}$, \\ Richard A. Fuller ${ }^{1,5}$, Robert L. Pressey ${ }^{6}$ and Hugh P. Possingham ${ }^{1,7}$
}

\begin{abstract}
Tropical montane cloud forests are among the most vulnerable terrestrial ecosystems to climate change ${ }^{1-3}$ owing to their restricted climatic requirements and their narrow and fragmented distribution ${ }^{4}$. Although $12 \%$ of Mexican cloud forest is protected, it is not known whether reserves will ensure the persistence of the ecosystem and its endemic species under climate change. Here, we show that $68 \%$ of Mexico's cloud forest could vanish by $\mathbf{2 0 8 0}$ because of climate change and more than $90 \%$ of cloud forest that is protected at present will not be climatically suitable for that ecosystem in 2080 . Moreover, if we assume unprotected forests are cleared, $99 \%$ of the entire ecosystem could be lost through a combination of climate change and habitat loss, resulting in the extinction of about $\mathbf{7 0} \%$ of endemic cloud forest vertebrate species. Immediate action is required to minimize this loss-expansion of the protected-area estate in areas of low climate vulnerability is an urgent priority. Our analysis indicates that one key area for immediate protection is the Sierra de Juárez in Oaxaca. This area supports many endemic species and is expected to retain relatively large fragments of cloud forest despite rapid climate change.
\end{abstract}

Cloud forests occur only within narrow altitudinal limits and contain a highly specialized suite of species dependent on montane topography and cloud-related microclimates. In Mexico, cloud forests account for $1 \%$ of land area, but support the highest concentration of plant and animal diversity of any Mexican ecosystem and they constitute the second richest ecosystem for endemic terrestrial vertebrates in Mesoamerica ${ }^{5}$. Although habitat loss and degradation by human encroachment are the chief contemporary threats to cloud forests globally ${ }^{6}$, the narrow environmental tolerance of this ecosystem indicates that humaninduced climate change could constitute an even greater peril in the near future. Changes in regional temperature and precipitation patterns are already influencing the extent and distribution of these forests $^{1,2}$, so it is essential that we understand how future climate change will affect cloud forests ${ }^{7}$.

Based on climate projections for 2080, we estimated the potential distribution and extent of Mexican cloud forests and the loss of cloud forest endemic species due to habitat loss (see Methods). We forecasted the present and future overlap with protected areas ${ }^{8}$ for two different scenarios. In the first scenario we estimated only the climate-driven threat, and in the second, we added the impacts of potential land-use change. To account for uncertainties inherent in

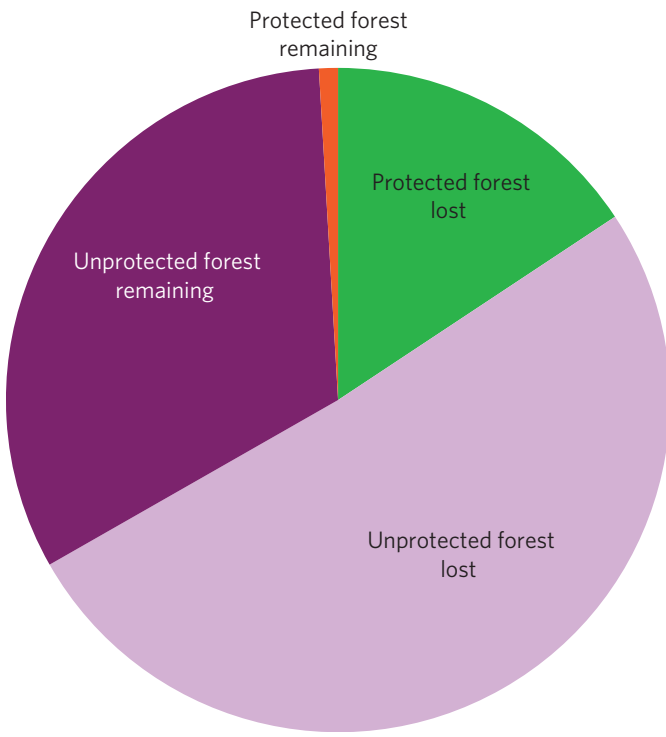

Figure 1 | Cloud forest extent and protection for $\mathbf{2 0 1 0}$ and 2080. The total area of Mexican cloud forest in 2010 was $17,320 \mathrm{~km}^{2}$. Cloud forest that is unprotected at present but predicted to remain climatically suitable for cloud forest in $2080\left(5,600 \mathrm{~km}^{2}\right)$ is shown in dark purple. Unprotected cloud forest predicted to become climatically unsuitable by 2080 $\left(8,850 \mathrm{~km}^{2}\right)$ is coloured light purple. Protected cloud forest predicted to be climatically suitable in $2080\left(160 \mathrm{~km}^{2}\right)$ is orange and protected forest predicted to be climatically unsuitable by $2080\left(2,710 \mathrm{~km}^{2}\right)$ is green

climate projections ${ }^{7}$ our distribution modelling was based on a consensus approach using seven global circulation predictions based on the Special Report on Emissions Scenarios (SRES) A1B emissions scenario (see Methods). We preferred the use of the global circulation models instead of building a regional climate model for Mexico because of the potentially limited accuracy of a regional model ${ }^{9}$. Owing to strict climatic requirements, slow growth, short dispersal distances, poor competitive ability and an archipelagic distribution, it is likely that the rate at which suitable conditions for cloud forests are reduced spatially will be orders of magnitude greater than the potential expansion rate of cloud forests ${ }^{4}$. There is evidence of long-distance dispersal of cloud forests' seeds ${ }^{6}$; however, even assuming that propagules arrive in an area with suitable climatic

\footnotetext{
${ }^{1}$ School of Biological Sciences, University of Queensland, St Lucia, Queensland 4072, Australia, ${ }^{2}$ Instituto de Biología, Universidad Nacional Autónoma de México, México DF, CP.04510, México, ${ }^{3}$ Global Conservation Programs, Wildlife Conservation Society, Bronx, New York 10460, USA, ${ }^{4}$ Centre for Tropical Biodiversity and Climate Change Research, James Cook University, Townsville, Queensland 4811, Australia, ${ }^{5}$ CSIRO Climate Adaptation Flagship and CSIRO Ecosystem Sciences, 41 Boggo Road, Dutton Park, Queensland 4102, Australia, ${ }^{6}$ ARC Centre of Excellence for Coral Reef Studies, James Cook University, Townsville, Queensland 4811, Australia, ${ }^{7}$ ARC Centre of Excellence for Environmental Decisions, University of Queensland, St Lucia 36, Queensland 4072, Australia. *e-mail: r.ponce@uq.edu.au.
} 


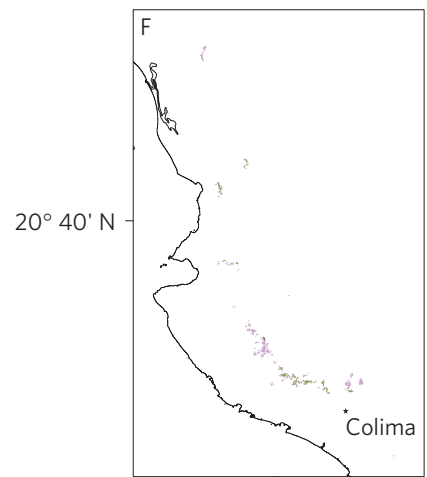

$104^{\circ} 25^{\prime} \mathrm{W}$

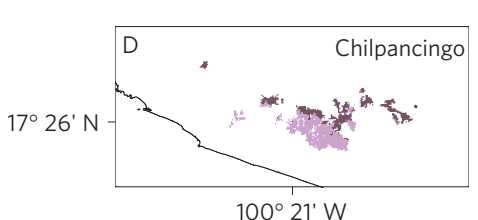

$100^{\circ} 21^{\prime} \mathrm{W}$

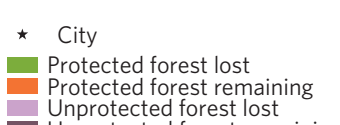

Unotected forest remain

Unprotected forest remaining
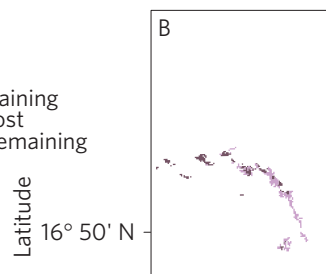

B
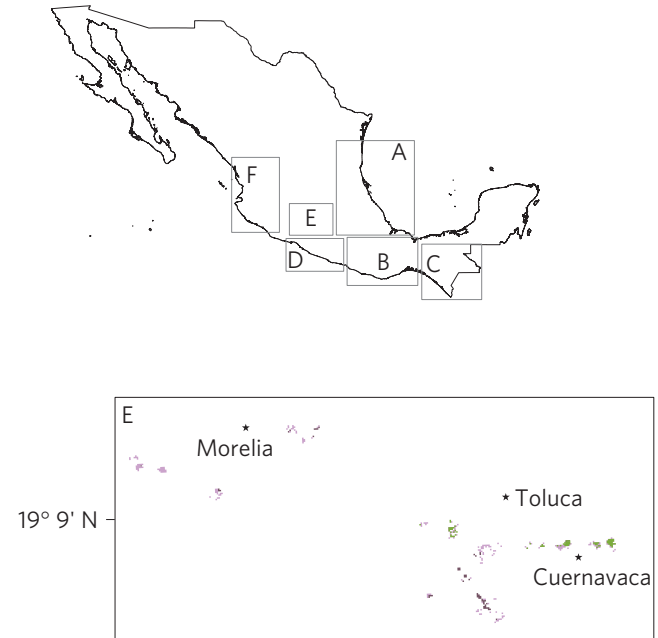

$100^{\circ} 21^{\prime} \mathrm{W}$

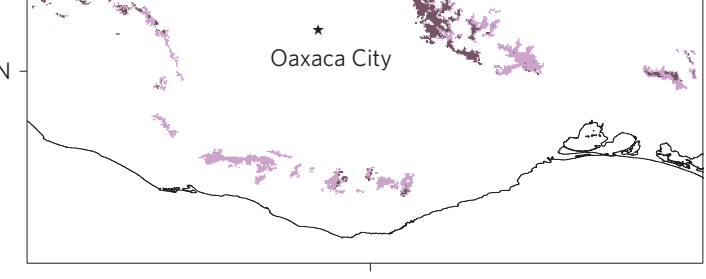

$96^{\circ} 22^{\prime} \mathrm{W}$

Longitude
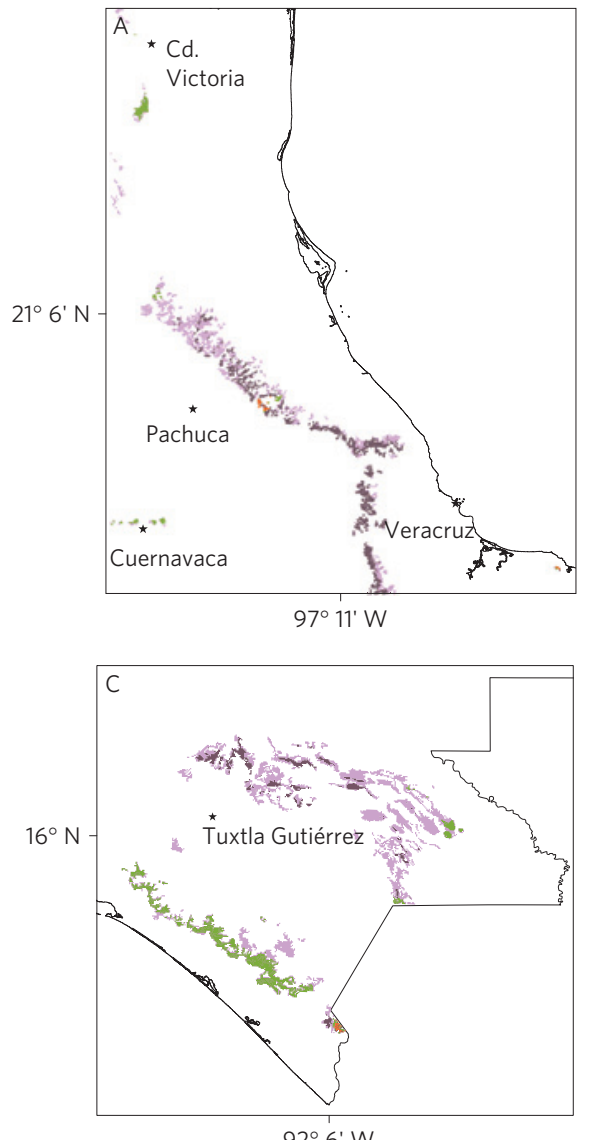

$92^{\circ} 6^{\prime} \mathrm{W}$

Figure 2 | Present and projected distribution of Mexican cloud forest. The colour scheme follows that of Fig. 1. A, Sierra Madre Oriental; B, Oaxaca with the Sierra de Juárez marked by a rectangle; C, Chiapas; D, Sierra Madre del Sur; E, Eje Transvolcánico; and F, Sierra Madre Occidental.

Table 1 | Present extent of Mexican cloud forest by region and coverage by protected areas.

\begin{tabular}{|c|c|c|c|c|c|}
\hline & Region & $\begin{array}{l}\text { Cloud forest extent } \\
\left(\mathrm{km}^{2}\right)\end{array}$ & $\begin{array}{l}\text { Cloud forest in protected } \\
\text { areas } 2010\left(\mathrm{~km}^{2}\right)\end{array}$ & $\begin{array}{l}\text { Remaining cloud forest } \\
\text { under scenario } 1\left(\mathrm{~km}^{2}\right)\end{array}$ & $\begin{array}{l}\text { Remaining cloud forest } \\
\text { under scenario } 2\left(\mathrm{~km}^{2}\right)\end{array}$ \\
\hline A & Sierra Madre Oriental & 3,768 & 201 & 1,694 & 33 \\
\hline B & Oaxaca & 5,160 & 175 & 2,326 & 65 \\
\hline C & Chiapas & 6,037 & 1,687 & 797 & 45 \\
\hline D & Guerrero & 1,556 & 4 & 685 & 4 \\
\hline$E$ & Eje Transvolcánico & 255 & 83 & 41 & 3 \\
\hline \multirow[t]{2}{*}{$\mathrm{F}$} & Sierra Madre Occidental & 498 & 142 & 14 & 2 \\
\hline & Total & 17,274 & 2,045 & 5,557 & 151 \\
\hline
\end{tabular}

Scenario 1 assumes that all cloud forest in areas remaining climatically suitable in 2080 remains intact, whereas scenario 2 assumes all unprotected cloud forest is cleared.

conditions (and no competition), they would still need between 200 and 300 years to become established. For this reason, we restricted predictions of suitable environments to areas within the present distribution of cloud forest, essentially assuming that cloud forest is unable to colonize new areas within the short time frame of this analysis (70 years). We derived the number of vertebrate species by searching the literature $e^{5,10}$ and updated it with data from the International Union for Conservation of Nature red list, AmphibiaWeb (http://amphibiaweb.org/), Avibase (http://avibase.bsc-eoc.org/), BirdLife International (http://www.birdlife.org) and experts (see Acknowledgements). We then estimated the persistence of these endemic species under both scenarios using two different approaches: first, the species-area curve; and second, the overlap of our models with distributional range maps for each species.

Climatically suitable areas for cloud forest in Mexico will decline by $68 \%$ to about $5,600 \mathrm{~km}^{2}$ by 2080 (Figs 1,2 and Table 1), so we expect the distribution of cloud forest to decline by at least this area. Protected areas cover about $12 \%$ of today's Mexican cloud forests, but the protected-area estate barely overlaps $(<1 \%$, covering $160 \mathrm{~km}^{2}$ ) with areas that are climatically suitable for cloud forest in 2080 (Fig. 1, see Methods). Regional analyses of the spatial distribution of protected areas highlight the unfortunate location of most of them (Table 1). Chiapas (box C in Fig. 2), in the southeast of Mexico, has the largest extent of cloud forests $\left(6,037 \mathrm{~km}^{2}\right)$ with 
Table 2 | Predicted changes in habitat area $\left(A, \mathrm{~km}^{2}\right)$ and number of endemic vertebrate species $(S)$ in Mexican cloud forest.

\begin{tabular}{|c|c|c|c|c|c|c|c|}
\hline & Region & $S_{0}$ & $A_{0}$ & $S_{1}$ & $A_{1}$ & $S_{2}$ & $A_{2}$ \\
\hline A & Sierra Madre Oriental & 4 & 3,768 & 3 & 1,694 & 1 & 33 \\
\hline B & Oaxaca & 26 & 5,160 & 21 & 2,326 & 9 & 65 \\
\hline C & Chiapas & 3 & 6,037 & 2 & 797 & 1 & 45 \\
\hline D & Guerrero & 4 & 1,556 & 3 & 685 & 1 & 4 \\
\hline $\mathrm{E}$ & Eje Transvolcánico & 0 & 255 & 0 & 41 & 0 & 3 \\
\hline \multirow[t]{2}{*}{$F$} & Sierra Madre Occidental & 0 & 498 & 0 & 14 & 0 & 2 \\
\hline & All & 37 & 17,274 & 28 & 5,557 & 11 & 151 \\
\hline
\end{tabular}

Subscripts indicate present values (0), values for 2080, with reduction owing to climate change, assuming all unprotected cloud forest remains intact (1) and values for 2080 assuming the effects of both climate change and clearing of all unprotected cloud forest (2). Regional values for species sum to less than the total because some species occur in more than one region.

about a quarter of those forests protected at present (Table 1). However, the climatic conditions predicted to occur in 2080 will be unsuitable for cloud forest across $87 \%$ of its present distribution in this region. Of this area, only about $33 \mathrm{~km}^{2}(<1 \%)$ corresponds with remaining forest under our second scenario (Table 1 , box $\mathrm{C}$ in Fig. 2). The opposite is the case in Oaxaca (box B in Fig. 2), where only $175 \mathrm{~km}^{2}(3 \%)$ of the $5,160 \mathrm{~km}^{2}$ of cloud forests occurring there are protected at present. Of the present extent, about $2,326 \mathrm{~km}^{2}$ $(45 \%)$ is predicted to remain if no further anthropogenic clearing occurs, but only $66 \mathrm{~km}^{2}$ will remain if all unprotected forest is cleared by 2080 . These results identify a serious spatial mismatch between areas that are protected at present and those likely to remain after near-term climate change, and highlight the importance of considering the probability of persistence of cloud forests under climate change when designating areas for conservation.

According to our calculations based on a species-area curve, the loss of cloud forest directly attributable to climate change would lead to the extinction of 9 of the 37 vertebrates restricted to a region of Mexican cloud forest (see Methods and Table 2). Furthermore, if all unprotected cloud forest is cleared, we estimate that 26 endemic vertebrate species could be lost across the Mexican cloud forest as a whole (see Methods). The results of overlapping the distributional range maps were even more striking, with the geographic ranges of 18 of the 37 vertebrate species overlapping by less than $10 \%$ with climatically suitable areas for cloud forests in 2080 (Supplementary Table S2). The distributions of 30 species did not overlap at all with climatically suitable areas remaining within protected areas in 2080 (Supplementary Table S2). Chiapas was one of the regions proportionately most exposed to losses of endemic species, with one of its three endemic species threatened under the first scenario and two species under the second scenario (box $\mathrm{C}$ in Fig. 2, Table 2). In contrast, in Oaxaca between $15 \%$ and $65 \%$ of the 26 species restricted to cloud forest in the region are expected to disappear according to our first and second scenario, respectively (box B in Fig. 2, Table 2).

Cloud forest seems to be among the world's terrestrial ecosystems most vulnerable to short-term climate-change impacts. Our prediction of a loss of $68 \%$ of climatically suitable habitat for Mexican cloud forest is consistent with the loss of $65 \%$ of Costa Rican cloud forest predicted in 1992 (ref. 11). Although changes in climate and land use are not the only threats to cloud forests, they could catalyse the impact of other threats, such as chytridiomycosis, the fungal infection that is affecting large numbers of amphibian species in the tropics ${ }^{1,12}$. Adjustments in cloud forest assemblages in response to climate change are already noticeable in other parts of the world (for example, Costa Rica ${ }^{1}$ ). The decline in climatically suitable areas for cloud forest may not result in the immediate loss of the cloud forest, but the vegetation communities will probably be transformed as the ecological processes that structure them are altered by a changing climate ${ }^{13}$. Recent studies have analysed the impacts of deforestation on cloud formation over cloud forests ${ }^{7}$,

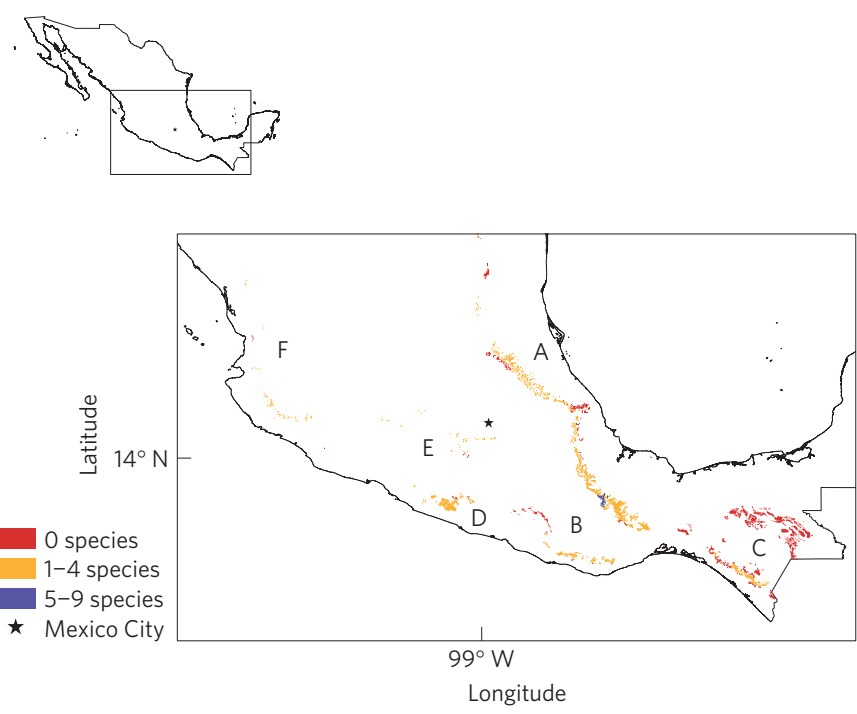

Figure 3 | Overlap of geographic ranges of vertebrates restricted to a single cloud forest region with the present extent of cloud forest. Areas coloured red have no endemic vertebrate species; areas in orange have between one to four species and the blue region (Sierra de Juárez) has between five and nine species. A, Sierra Madre Oriental; B, Oaxaca with the Sierra de Juárez marked by a rectangle; C, Chiapas; D, Sierra Madre del Sur; E, Eje Transvolcánico; and F, Sierra Madre Occidental.

the shifting trends in regional precipitation and fog frequency ${ }^{7}$, and the impacts of fire due to climate changes ${ }^{7}$. However, we have delineated the areas of high climatic vulnerability and shown how poorly protected areas are aligned with those vulnerable areas, as well as predicted the loss of endemic species as a result of climate change.

Deforestation in Latin America's tropical areas is expected to be one of the most serious biodiversity impacts in the region ${ }^{14}$. The deforestation rate in Mexico during the second half of the twentieth century is among the highest in the world ${ }^{15-17}$ and the $1.1 \%$ annual deforestation rate of montane tropical forests is the highest among all tropical vegetation types ${ }^{6}$. We therefore expect that the most likely scenario is for cloud forest to become increasingly restricted to protected areas. It would be interesting to model future deforestation empirically using recently available techniques based on environmental and socio-economic parameters (see refs 18,19 for a review). Nonetheless, in the case of Mexico at least, the present protected-area estate barely overlaps with places where forest will persist in a rapidly changing climate.

Several actions could be taken to enhance the persistence of the Mexican cloud forests. A first could be to increase the number of protected areas in regions of predicted climatic suitability for forest persistence. This could prevent land-use change from eliminating 
tracts of cloud forest that are buffered from climate change. However, the participation of traditional land owners is required if new protected areas are designated. One candidate for protection is the Sierra de Juárez (box B in Fig. 2), a region of high endemism (Fig. 3) where much of the large fragment of cloud forest seems likely to remain climatically suitable for that habitat type until at least 2080 (box B in Fig. 2). Of the 157 priority species that the Alliance for Zero Extinction ${ }^{20}$ (www.zeroextinction.org) identified across Mexico, 22 occur only in the Sierra de Juárez and the area has been designated as an Alliance for Zero Extinction site. Given that land clearing does still occur within protected areas ${ }^{21}$, protection of new sites alone might be insufficient. Improved management of existing protected areas will also enhance the conservation status of Mexican cloud forests and their species, and more radical conservation interventions such as assisted colonization ${ }^{22,23}$ of species occurring in areas of high climatic vulnerability might be worthwhile in this instance, not least because many species endemic to cloud forest have narrow and fragmented global distributions. Finally, if bold measures are not taken very soon to reduce the concentration of greenhouse gases, these forests are unlikely to survive in their present configuration and with anything near their present diversity very far into the twenty-first century.

\section{Methods}

Modelling the distribution of cloud forest. We used Maxent version 3.33 (ref. 24), a presence-only distribution-modelling algorithm, to model the present extent of Mexican cloud forest based on climatic variables, then projected this model to future climate scenarios for 2080. We obtained a map of present cloud forest distribution from the Mexican government ${ }^{25}$ and converted this into a one-kilometre presence/absence grid for analysis. We randomly selected 1,317 grid cells (square root of the total extent) to use as presence points to train the model and generated 30,000 background points across Mexico. We evaluated model performance using tenfold cross-validation, and calculated the mean area under the receiver operating characteristic curve (AUC; ref. 26). We used the AUC as a metric to compare among models without using thresholds. The AUC indicates the probability that a randomly chosen presence site will be ranked above a randomly chosen absence site ${ }^{24}$. An AUC score above 0.7 is considered good model performance ${ }^{27}$. Resulting mean AUC values of all models were between 0.961 and 0.962 , indicating excellent prediction of present-day cloud forest distribution and confirming the utility of these models for making projections of future forest distributions. We converted the logistic output from Maxent into a presence/absence grid using the threshold at which training sensitivity equalled specificity $^{28}$, in other words, where positive and negative observations have an equal chance of being correctly predicted ${ }^{27}$.

Uncertainty. To account for the uncertainties inherent in climate projections we took a consensus approach using seven global circulation models based on the SRES A1B emissions scenario. This is represented in Supplementary Fig. S1, darker blue and red colours indicate increasing certainty in predictions of presence or absence of cloud forest, respectively. We assumed that if climate data from a majority of global circulation models (four or more) predicted presence in an area, the balance of evidence was that the area would retain cloud forest in 2080 (all blue colours in Supplementary Fig. S1). If fewer than four models predicted presence, our consensus model indicated forest loss (all red colours in Supplementary Fig. S1). We used this threshold of agreement among four models to report our primary results on the future distribution of cloud forest and the extinctions of endemic species, and sensitivity analysis indicated that the results were robust to the exact choice of threshold (see Supplementary Information).

Climate data. Present climate data were obtained from WorldClim ${ }^{29}$ version 1.4 at a resolution of 30 arcsec. Some authors have criticised the performance of WorldClim in montane systems because considerable variation in temperature can occur within one square kilometre ${ }^{30}$. However, others have demonstrated that WorldClim reflects well the data from weather stations in close proximity to cloud forests $^{31}$. Future climate predictions at the same resolution for 2080 based on the SRES A1B scenario ${ }^{32,33}$ were obtained from the International Centre for Tropical Agriculture (ref. 33) for seven alternative global circulation models, namely CCCMA-CGCM31, CSIRO-MK30, IPSL CM4, MPI ECHAM5, NCAR CCSM30, UKMO HADCM3 and UKMO HADGEM1. These models predict an increase in global mean temperature of between 1.7 and $4.4{ }^{\circ} \mathrm{C}$, thus covering a wide range of possible future climates. Scenario A1B is an emissions scenario reflecting balanced energy sources. It is part of the Al family of scenarios representing an integrated world with fast economic growth and with a rapid spread of new and efficient technologies ${ }^{32}$.
We selected the following biologically relevant climate variables for developing the distribution models: annual mean temperature, temperature seasonality, mean temperatures of the coldest and warmest quarters, annual mean precipitation, precipitation seasonality and mean precipitation of wettest and driest quarter ${ }^{29}$ We also used data on soil types to characterize areas suitable for cloud forest formation ${ }^{34}$. Factors such as cloud frequency, fog presence and wind speed and direction may significantly affect the formation and maintenance of cloud forests, but as there are no reliable data on their likely trajectories under future climates we couldn't consider them directly here ${ }^{7}$. We discarded altitude as a predictor because it is a surrogate for climatic variables rather than a direct driver of habitat suitability.

Estimating extinctions of endemic species. Cloud forests have a fragmented distribution, so we calculated the impact of habitat loss on species persistence separately for six regions in the Mexican cloud forest system. Forty-two vertebrate species of Mexican cloud forest endemics with available distributional range maps that overlapped present cloud forest are restricted to one region only (Supplementary Table S1). This figure was calculated based on the only list of vertebrates for Mexico ${ }^{5}$ but updated with data from the International Union for Conservation of Nature red list, AmphibiaWeb, Avibase, Birdlife International, literature $\mathrm{r}^{10}$ and experts (see Acknowledgements). To estimate the number of endemic species at risk of extinction through habitat loss we followed two approaches: first, a simple species-area relationship ${ }^{3}$; and second, overlapping the range maps with our consensus models to predict which parts of the geographic distributions of species will be lost and which will remain.

Species-area relationship. The species-area relationship had the form of $S=c A^{z}$ where $S$ is the number of species, $A$ is habitat area and $c$ (the $y$-intercept) and $z$ (the slope) are constants. We used $z=0.25$ given that cloud forest is a fragmented habitat with high species richness ${ }^{35}$. Values of $A$ corresponding to present cloud forest, its predicted future extent under climate change and the remaining cloud forest that overlaps protected areas are, respectively, $A_{0}=17,274 \mathrm{~km}^{2}$, $A_{1}=5,557 \mathrm{~km}^{2}$ and $A_{2}=151 \mathrm{~km}^{2}$. Values of $A$, together with species richness and extinction estimates for these regions, are shown in Table 2.

Geographic distributions. We overlaid the distributional range maps for each species with: first, the present distribution of cloud forests (CF 2010; Fig. 3; Supplementary Table S1); second, the present cloud forest within a protected area (CF PA 2010; Supplementary Table S1); third, our consensus model of suitable areas of cloud forest distribution under a climate-change scenario for 2080 (CF 2080; Supplementary Table S1); and fourth, the suitable areas for cloud forests within protected areas for 2080 (CF PA 2080; Supplementary Table S1; assuming that land-use change will result in all unprotected forest being cleared).

\section{Received 2 September 2011; accepted 15 February 2012;} published online 18 March 2012

\section{References}

1. Pounds, A. J., Fogden, M. P. L. \& Campbell, J. H. Biological response to climate change on a tropical mountain. Nature 398, 611-615 (1999).

2. Still, C. J., Foster, P. N. \& Schneider, S. H. Simulating the effects of climate change on tropical montane cloud forests. Nature 398, 608-610 (1999).

3. Thomas, C. D. et al. Extinction risk from climate change. Nature 427, 145-148 (2004).

4. Foster, P. The potential negative impacts of global climate change on tropical montane cloud forests. Earth Sci. Rev. 55, 73-106 (2001).

5. Flores-Villela, O. \& Gerez, P. Biodiversidad y Conservación en México: Vertebrados y uso de Suelo (Comisión Nacional para el Uso y Conservación de la Biodiversidad, Universidad Nacional Autónoma de México, 1994).

6. Hamilton, L. S., Juvik, J. O. \& Scatena, F. N. (eds) Tropical Montane Cloud Forests (Springer, 1995).

7. Bruijinzeel, L. A., Scatena, F. N. \& Hamilton, L. S. (eds) Tropical Montane Cloud Forests: Science for Conservation and Management (Cambridge Univ. Press, 2010).

8. IUCN \& UNEP-WCMC The World Database on Protected Areas (2010); available at http://www.protectedplanet.net.

9. Estrada, F., Martinez-Lopez, B., Conde, C. \& Gay-Garcia, C. The new national climate change documents of Mexico: What do the regional climate change scenarios represent? Climatic Change 10, 1-18 (2011).

10. Ceballos, G. \& Oliva, G. (eds) Los Mamiferos Silvestres de Mexico (Fondo de Cultura Económica, 2005).

11. Tosi, J. A. J., Watson, V. \& Echeverria, J. Potential Impacts of Climatic Change on the Productive Capacity of Costa Rican Forests: A Case Study (Tropical Science Center, 1992).

12. Pounds, A. J. et al. Widespread amphibian extinctions from epidemic disease driven by global warming. Nature 439, 161-167 (2006).

13. Bush, M. B., Silman, M. R. \& Urrego, D. H. 48,000 years of climate and forest change in a biodiversity hot spot. Science 303, 827-829 (2004).

14. Magrin, G. et al. in IPCC Climate Change 2007: Impacts, Adaptation and Vulnerability (eds Parry, M. L., Canziani, O. F., Palutikof, J. P., van der Linden, P. J. \& Hanson, C. E.) Ch. 13 (Cambridge Univ. Press, 2007). 
15. Cairns, M. A., Dirzo, R. \& Zadroga, F. Forests of Mexico: A diminishing resource? J. For. 93, 21-24 (1995).

16. Masera, O., Ordoñez, M. J. \& Dirzo, R. in Carbon Emissions and Sequestration in Forests: Case Studies from Seven Developing Countries (eds Makundi, W. \& Sathaye, J.) (Univ. California, 1992).

17. Sayer, J. A. \& Whitmore, T. C. Tropical moist forests: Destruction and species extinction. Biol. Con. 55, 199-213 (1991).

18. Pereira, H. M. et al. Scenarios for global biodiversity in the 21 st century. Science 330, 1496-1501 (2010)

19. Soares-Filho, B. S. et al. Modelling conservation in the Amazon basin. Nature 440, 520-523 (2006).

20. Ricketts, T. H. et al. Pinpointing and preventing imminent extinctions. Proc. Natl Acad. Sci. USA 102, 18497-18501 (2005).

21. Joppa, L. N. \& Pfaff, A. Re-assessing the forest impacts of protection: The challenge of non-random location \& a corrective method. Annu. Rev. Ecol. Econ. 1185, 135-149 (2010).

22. Hoegh-Guldberg, O. et al. Assisted colonization and rapid climate change. Science 321, 345-346 (2008).

23. McDonald-Madden, E., Runge, M. C., Possingham, H. P. \& Martin, T. G. Optimal timing for managed relocation of species faced with climate change. Nature Clim. Change 1, 261-265 (2011).

24. Phillips, S. J. \& Dudík, M. Modeling of species distributions with Maxent: New extensions and a comprehensive evaluation. Ecography 31, 161-175 (2008).

25. Instituto Nacional de Estadística y Geografía Carta de Uso Actual del Suelo y Vegetación Serie III (Instituto Nacional de Estadística y Geografía, 2005).

26. Hanley, J. A. \& McNeil, B. J. The meaning and use of the area under a receiver operating characteristic (ROC) curve. Radiology 143, 29-36 (1982).

27. Fielding, A. H. \& Bell, J. F. A review of methods for the assessment of prediction errors in conservation presence/absence models. Environ. Conserv. 24, 38-49 (1997)

28. Liu, C., Berry, P. M., Dawson, T. P. \& Pearson, R. G. Selecting thresholds of occurrence in the prediction of species distributions. Ecography 28, 385-393 (2005).
29. Hijmans, R. J. et al. Very high resolution interpolated climate surfaces for global land areas. Int. J. Climatol. 25, 1965-1978 (2005).

30. Machac, A., Janda, M., Dunn, R. \& Sanders, N. J. Elevational gradients in phylogenetic structure of ant communities reveal the interplay of biotic and abiotic constraints on diversity. Ecography 24, 364-371 (2010).

31. Jarvis, A. \& Mulligan, M. in Tropical Montane Cloud Forests: Science for Conservation and Management (eds Bruijinzeel, L. A., Scatena, F. N. \& Hamilton, L. S.) (Cambridge Univ. Press, 2010).

32. IPCC Climate Change 2007: Impacts, Adaptation and Vulnerability (eds Parry, M. L., Canziani, O. F., Palutikof, J. P., vander Lunden, P. J., \& Hanson, C. E.) (Cambridge Univ. Press, 2007).

33. Ramirez, J. \& Jarvis, A. High Resolution Statistically Downscaled Future Climate Surfaces (International Centre for Tropical Agriculture, 2008).

34. Instituto Nacional de Investigaciones Forestales y Agropecuarias Comisión Nacional Para el Conocimiento y Uso de la Biodiversidad (INIFAP, 1995).

35. Rosenzweig, M. L. Species Diversity in Space and Time (Cambridge Univ. Press, 1995).

\section{Acknowledgements}

We thank M. A. Gurrola and A. González-Hernández for help compiling data. This work is financially supported by the Consejo Nacional de Ciencia y Tecnología, Rufford Small Grants for Conservation, an Australian Research Council Federation Fellowship to H.P.P. and the Australian Research Council Centre of Excellence for Environmental Decisions.

\section{Author contributions}

R.P-R., J.E.M.W., V-H.R., J.V., R.L.P. and H.P.P. designed the study. R.P-R. carried out the research. R.P-R. and R.A.F. analysed the data. All the authors wrote the paper.

\section{Additional information}

The authors declare no competing financial interests. Supplementary information accompanies this paper on www.nature.com/natureclimatechange. Reprints and permissions information is available online at www.nature.com/reprints. Correspondence and requests for materials should be addressed to R.P-R. 